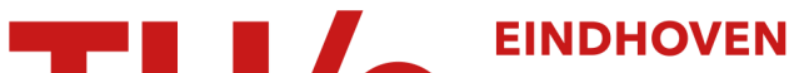 \\ UNIVERSITY OF \\ TECHNOLOGY
}

\section{Forecasting and recruitment in graded manpower systems}

\author{
Citation for published version (APA): \\ van Nunen, J. A. E. E., \& Wessels, J. (1977). Forecasting and recruitment in graded manpower systems. \\ (Memorandum COSOR; Vol. 7708). Technische Hogeschool Eindhoven.
}

Document status and date:

Published: 01/01/1977

\section{Document Version:}

Publisher's PDF, also known as Version of Record (includes final page, issue and volume numbers)

\section{Please check the document version of this publication:}

- A submitted manuscript is the version of the article upon submission and before peer-review. There can be important differences between the submitted version and the official published version of record. People interested in the research are advised to contact the author for the final version of the publication, or visit the $\mathrm{DOI}$ to the publisher's website.

- The final author version and the galley proof are versions of the publication after peer review.

- The final published version features the final layout of the paper including the volume, issue and page numbers.

Link to publication

\section{General rights}

Copyright and moral rights for the publications made accessible in the public portal are retained by the authors and/or other copyright owners and it is a condition of accessing publications that users recognise and abide by the legal requirements associated with these rights.

- Users may download and print one copy of any publication from the public portal for the purpose of private study or research.

- You may not further distribute the material or use it for any profit-making activity or commercial gain

- You may freely distribute the URL identifying the publication in the public portal.

If the publication is distributed under the terms of Article 25fa of the Dutch Copyright Act, indicated by the "Taverne" license above, please follow below link for the End User Agreement:

www.tue.nl/taverne

Take down policy

If you believe that this document breaches copyright please contact us at:

openaccess@tue.nl

providing details and we will investigate your claim. 


\section{EINDHOVEN UNIVERSITY OF TECHNOLOGY}

Department of Mathematics

PROBABILITY THEORY, STATISTICS AND OPERATIONS RESEARCH GROUP

Memorandum $\operatorname{COSOR} 77-08$

FORECASTING AND RECRUITMENT IN

GRADED MANPOWER SYSTEMS

by

J.A.E.E, van Nunen and J. Wessels

Eindhoven, Apri1 1977

The Netherlands 
FORECASTING AND RECRUITMENT IN GRADED MANPOWER SYSTEMS

J.A.E.E. van Nunen

Graduate School of Management, Delft, the Netherlands

J. Wessels

University of Technology, Dept. of Math., Eindhoven, the Netherlands

\section{ABSTRACT}

In this paper a generalized Markov model is introduced to describe the dynamic behaviour of an individual employee in a graded Manpower system. Characteristics like the employee's grade, his educational level, his age and the time spent in his actual grade, can be incorporated in the Markov model. On this Markov model forecasting and recruitment scheduling procedures are based. The procedures enable us to study for example the consequences of planned promotion and recruitment policies on futural grade occupancies, age distribution etc. Moreover recruitment requested for satisfying futural grade occupancies can be determined.

\section{Introduction}

The subject of this paper is the dynamic behaviour and control of a graded manpower system. As basic tool we will use a general Markov chain model for the dynamic behaviour of an individual employee. In our general model the well-known disadvantages of the standard Markov chain modèl are neutralized. The model will be described in section 2. In section 3 the forecasting procedure based on the Markov Model is discussed. It is demonstrated how the forecasting procedure can be used to get insight in phenomena like mean time spent in a certain grade, and age distribution in the future.

In section 4 a recruitment planning procedure is introduced which exploits the dynamic behaviour of a Manpower system. Recruitment is allowed for some or for all grades. The procedure consists of a blending of forward and backward dynamic programming. 
The basic procedure may be used for several planning aims and side conditions like restricted recruitment. Those aims and conditions may in turn restrict the amount of backwards induction. In reference [5] it is argued why in our opinion the dynamic approach for recruitment planning is preferable to the linear programming approach as described e.g. in $\mid 1],[5]$. Here the side conditions and the place of Manpower planning in an organisation play an essential role. In the final section it is indicated how a manpower data system in combination with a forecasting and recruitment planning procedure may yield a very important instrument for manpower management. Such a system may be used to achieve the relevant information concerning e.g. actual and futural distribution of manpower with respect to several criteria like age, grade and so on. With respect to the future such a system enables one to study the impact of policy changes with respect to promotion and recruitment. Moreover, it can be used to determine the requested recruitment if the promotion policy is given.

The ideas and notions exhibited in this and a foregoing paper [5] are being incorporated in a computer system for forecasting and recruitment in graded manpowar systems. This system, called roRMASY, is developed at Eindhoven University of Technology.

We are grateful for many discussions with our colleagues $\mathrm{Dr}$. Jacob Wijngaard and Kees Verhoeven, who cooperate with us in this work in progress.

\section{The general Markov model for individual employees}

In the standard Markov chain model for the dynamic behaviour of an individual employee it is supposed that the employee jumps from one grade to another until he finally leaves the system. In such a model transition probabilities depend on the current grade but they should not depend on features like experience, age, time spent in the grade. However, in order to obtain a realistic model, transition probabilities should also depend on such features. This can be obtained by introducing an extended concept of state for the Markov chain (see e.g. Forbes [3], Wessels and van Nunen [5]).

In the following we will describe the features which are to be taken into account in our general Markov model.

1) Suppose a manpower system has $G$ grades or job categories, denoted by $1,2, \ldots, G$. Promotions are supposed to increase the grade numbers of an employee. The grade structure may be linear or branching.

2) Assume that the personal characteristics of an employee can be measured by:

a) A quantification index denoted by $q$ where $q$ runs from 1 to $Q$ (so $q \in\{1,2, \ldots, Q\})$. The qua'ification index may indicate an 
educational level and/or some classification for experiences. By the way, it may be possible to include experience in the grade level. It may also occur, for example in a closed system, that all employees have the same educational level and that the qualification index is used only to indicate e.g. managerial qualities of an employee.

b) An age index running from 1 to $A$. The age index may give the actual age of the employee. So A may be e.g. 40 if only employees between 20 and 59 years old populate the system. In another situation the age index may only indicate an age class e.g. $1: 20-29,2: 30-35,3: 36-45,4: 46-59$ (so $A=4)$.

c) A further important characteristic appeared to be the grade seniority or grade age, the time an employee already spent in his current grade. We assume the grade age $\ell$ to run from 0 to $\mathrm{L}$. Hence, when somebody is promoted to grade $g$ or enters the system in grade $g$ he usually gets the grade age 0 . In the practical problems we investigated, the grade age was a very important norm for promotability. For example, in a certain grade $g$ the "best" employees are always promoted to grade $\mathrm{g}+1$ after a stay of just 3 years. A "normal" promotion occurs after 4 years, while the remaining employees are promoted 5 years after their arrival in grade $g$. Note the relation between the age index and the grade age, sometimes this relation can be used to reduce the model.

If we take these features into account, we obtain a Markov chain model for the dynamic behaviour of an individual employee in which a person's state is characterized by four indices $g, q, a, l$ where

- $\mathrm{g}$ is his current grade $(\mathrm{g}=1, \ldots, \mathrm{G})$;

- $q$ is his current qualification index $(q=1, \ldots, Q)$;

- $a$ is his current age index $(a=1, \ldots, A)$;

- $\ell$ is his current grade age $(\ell=0,1, \ldots, L)$.

So this describes our general model. In specific situations the relative importance of the characteristics may differ substantially as is shown already by the following realistic examples.

\section{Example 1.}

A realistic example for the complete work force at the T.E.O. department at Philips, Eindhoven appeared to be as follows:

$-G=10$ (with salary groups as grades) and a linear grade structure;

- $Q=3$, with a linear structure and three educational levels as qualifications; experience is incorporated in the grade and in the (fictitious) educational level;

- $A=3$, with $1: 20-34,2: 35-44,3: 45-60$;

$-L=9$, after 9 years in the same grade the grade age is supposed to remain constant. 
In this way we get $\mathrm{G} \times \mathrm{Q} \times \mathrm{A} \times(\mathrm{L}+1)$ states. In the example $10 \times 3 \times 3 \times 10=900$, of which many are inessential.

Example 2.

At the Dutch Ministry of Public Works we met a closed subsystem with a linear grade structure with only five grades. In this system all the employees had the same educational level. The main characteristic for an employee in a grade was his grade age, which runs from 0 until 12 .

In this way we get for the number of states $G \times Q \times A \times(L+1)=$ $=5 \times 1 \times 1 \times 13=65$.

In general it will not be necessary to consider all the $G \times Q \times A \times(L+1)$ states: nobody will be in the top grade $G$ with qualification index 1 and age index 1 .

The first work is to make a set $\mathrm{S}_{2}$ of relevant states. This can be achieved in the following way:

1) Let $S_{1}$ contain only those states $(g, q, a, l)$ which may possibly occur in practice. In this way unlikely combinations as $(G, 1,1, \ell)$ and $(1, Q, A, l)$ are thrown away.

2) Lump together all states in $S_{1}$ that give the same expectations for the future. In the topgrades it may not be necessary to make difference between qualification indices. This gives $\mathrm{S}_{2}$.

In the first example there remained 39 relevant $(g, q, a)$ combinations (after the jumping) each generating maximally 10 states in $\mathrm{S}_{2}$ with the relevant grade ages.

In the second example the total number of states could be reduced only slightly. It will be clear that the number of relevant states will depend on the problem under study.

For administrative simplicity we introduce the state 0 for people who left the system. Hence leaving coincides with a transition from some state $(g, q, a, l)$ to state 0 .

A promotion coincides with a transition from some state $(g, q, a, l)$ to some state $\left(g_{1}, q_{1}, a_{1}, 0\right)$ with $g_{1}>g, q_{1} \geq q, a_{1} \geq a$.

If an employee did not leave the system in the course of a year and is not promoted, then he makes a transition from $(g, q, a, l)$ to $\left(g, q, a_{1}, \ell+1\right)$ if $\ell<L$. If $\ell=L$ he goes to $\left(g, q, a_{1}, L\right)$. In both situations it depends on the actual age classification whether $a_{1}$ equals a or $a+1$.

Now our set of states $S$ consists of 0 and the states in $S_{2}$.

A Markov chain model for the dynamic behaviour of an individual employee now only requires the specification of the transition probabilities.

The (transition) probability for an "arbitrary" employee to reach state " in one year if he is now in state $s$ is denoted by $p(s, 0)$. Since $\sum \mathrm{p}(s, 0)=1$ for $: s$ we have $\mathrm{p}(0,0)=1$. An important Dets

problem is the estimation of $p(s, \sigma)$. This problem is discussed e.g. 
in [5], and we will briefly return to it in the subsequent sections.

\section{Forecasting of futural distributions}

Now we turn from the behaviour of an individual to the dynamic behaviour of a manpower system consisting of several individuals. If we suppose that any individual behaves according to the general Markov model, we can easily compute expected distributions over the characteristics for the future. This can be done without assuming independent behaviour of the individuals (see [5]).

If at time $t=0$ there are $N_{S}(0)$ employees in state $s$, then the expected number (without recruitment) in state $\sigma$ at time $t=1$ is equal to

$$
\mathrm{N}_{\sigma}(1):=\sum_{\mathrm{s} \in \mathrm{S}} \mathrm{N}_{\mathrm{S}}(0) \mathrm{p}(\mathrm{s}, \sigma) .
$$

In vector notation, with $N(t)$ denoting the row vector of expected state occupancies at time $t$ and $P$ denoting the matrix of transition probabilities, we obtain

$$
\mathrm{N}(1)=\mathrm{N}(0) \mathrm{P} \text {. }
$$

For $N(t)$ with $t \geq 1$ we obtain similarly

$$
N(t)=N(0) P^{t} \text {. }
$$

If there is recruitment planned or foreseen, in numbers equaling $R_{S}(t)$ for state $s$ at time $t$, then the expected numbers at time $t$ become

$$
N(t)=N(0) P^{t}+R(1) P^{t-1}+\ldots+R(t-1) P+R(t) \text {. }
$$

Since the best forecast for the futural state occupancy distribu- . tions is the expected occupancy, this leads to a simple forecasting procedure.

The numbers $R_{S}(t)$ may be forecasts of the recruitment numbers. In that case the same formulas remain true if some independence conditions are satisfied.

Probably one is not really interested in forecasts for the occupancy of state $s$, but in some more aggregated statistics. However from the vector $N(t)$ one obtain such forecasts readily, e.g.

$$
\sum_{q, a, l}{ }^{N}(g, q, a, l)(t)
$$

is a forecast for the number of employees in grade $g$ at time $t$. Other features of interest are discussed in the final section.

For practical use of this forecasting procedures good estimates for the transition probabilities in $P$ are required. If the promotion policy has and will not be changed one may use historical data. Suppose in the year $-t$ there where $N_{s}(-t)$ employees in state $s$ and $n_{-t}(s, \sigma)$ of them jumped to state $\sigma$ between $-t$ and $-t+1$ (where 
$t=1,2, \ldots, k)$. Then see $|5|$ an estimate for $p(s, 0)$ is

$$
\left(\sum_{t=1}^{k} n_{-t}(s, \sigma)\right) \cdot\left(\sum_{t=1}^{k} N_{s}(-t)\right)^{-1} \text {. }
$$

If the historical data are obsolete or insufficient one has to use more sophisticated estimation techniques. It may even be possible that manpower managers use the forecast procedure with predicted or even fictitious transition probabilities in order to study the consequences for the future if the manpower system would behave in accordance with those probabilities. The quality of the forecasts depends of course on the quality of the model and on the "estimation" of the model parameters. Therefore it is essential that one does not use the model and the estimates for the transition probabilities blindly. A regular verification of the several aspects of the model is necessary. If all employees jump through the states independently from each other and if the transition probabilities are known exactly then the quality of the variables $\mathrm{N}_{\mathrm{S}}(\mathrm{t})$ can be characterize by their variances and covariances. For a description of the quality of the forecasts we refer to [1], [5]).

\section{Dynamic planning of recruitment}

In literature many aspects of controlling a graded manpower system have been studied. For an overview we refer to Bartholomew [1], chapter 4.

In principle a graded manpower system may be controlled by recruitment and by a promotion policy. The relative importance of both types of decisional options depends on the situation. In this paper we will consider the promotion policy as given and use recruitment as control variable. However, the described techniques may of course be used to study the consequences of a given different promotion policy, viz. by specifying matrix $P$. In fact, in the practical situation we met (as mentioned in section 2), the most frequent use of the model-including recruitment planning procedure - has been in finding out what the influence would be of changes in the promotion policy and which changes in the promotion policy would be necessary in order to obtain a required manpower distribution over the grades.

So the problem we have investigated in this section is the determination of the number $R_{S}(t)$ of employees to be recruited in state $s$ at $t$ ime $t$ for $s \in S$ and $t=0,1, \ldots, T$.

These numbers should satisfy a number of conditions like for example $R_{S}(t) \geq 0$ and $R_{S}(t) \leq \vec{R}_{S}(t)$, with $\vec{R}_{S}(t)$ a given upperbound. Moreover they should be such that conditions like e.g. $N_{S}(t) \geq \bar{N}_{s}(t)$, $t=0,1, \ldots, T-1 ; s \in S$, and $N_{S}(T)=\bar{N}_{S}(T), s \in S$, with $\bar{N}_{S}(t)$ and $\overline{\mathrm{N}}_{S}(\mathrm{~T})$ given "bounds" for state occupation, are satisfied. In practical situations the restrictions will in general not be given in terms of restrictions for each state separately but probably in 
terms of a restriction for a cluster of states. In the examples we met they were given in cerms of restrictions for each grade. Thereforewe restrict the considerations to the following problem. Decermine $R_{S}(t)$ for's $c S, t=0,1, \ldots, T$.

Subject to

$$
\begin{aligned}
& R_{s}(t)=0, s, S, t=0,1, \ldots, T \\
& R_{g}(t):=\sum_{q, a, l} R_{(g, q, a, l)}(t) \leq \bar{R}_{g}(t), \begin{array}{l}
g=1, \ldots, G, \\
t=0, \ldots, T
\end{array} \\
& \bar{N}_{g}(t) \leq \sum_{q, a, l} N_{(g, q, a, l)}(t)=: N_{g}(t), \begin{array}{l}
g=1, \ldots, G, \\
t=0, \ldots, T-1
\end{array} \\
& \bar{N}_{g}(t)=\sum_{q, a, l}{ }_{(g, q, a, l)}(T)=N_{g}(T), g=1, \ldots, G \\
& N_{g}(0)=N_{s}(0)+R(0), s t S \\
& N(t+1)=N(t) p(t)+R(t+1), t=0, \ldots, T-1
\end{aligned}
$$

where $\bar{N}_{g}(t), \bar{R}_{g}(t), \bar{N}_{g}(t)$ are given numbers.

Using linear programming it would be possible to compute for the above problem the set of values for $R_{S}(t)$ and $N_{S}(t)$ such that the total salarybill over the planningsperiod is minimal. Other options for the criterion function are possible, see [4], [5]. However, a more straightforward approach, in which the dynamic character is used in a more direct way will be presented here. For a discussion on advantages and disadvantages of the linear programming versus the dynamic programing approach see [5].

The framework of the dynamic approach is in fact very simple: First, compute for each grade the expected grade occupation for $t=0,1, \ldots, T$ if no recruitment takes place. Next, try to fill up by recruiting the resulting distances to the lowerbounds and targets. Start in grade $g=1$ at time $t=0$ with filling up by recruiting an eventual deficit with respect to $\mathrm{N}_{1}(0)$, and process the consequences of the recruitment in $g=1$ at $t=0$ in the forecasts for $g=1, \ldots, G$ and $t=1, \ldots, T$. Then an eventual deficit in grade $g=1$ at time $t=1$ is considered and so on. After grade $g=1$ we treat grade $g=2$ at time $t=0,1, \ldots, T$ respectively. We continue until grade $g=G$ at time $t=T$ is dispatched. Consequently, (within the side conditions) recruitment occurs as late as possible. In this way the total salary bill is guarded.

To satisfy the side conditions one has to recruite in general in a more sophisticated way. A detailed description of this more advanced method is given in the sequel of this section.

The first step will be to give forecasts for the situation without recruitment. 
STEP 1: Choose $R_{S}(t)=0(s+s, t=0,1, \ldots, T)$; Compute $N_{S}(t)$ $(s, s, t=0, \ldots, T)$.

As a consequence of STEP $I$ also $R_{g}(t)=0$ for $g=1, \ldots, G$, and $t=0, \ldots, T$. The second and third step investigate the deviations of the solution without recruitment from the given bounds and targets.

STEP 2: Compute $\mathrm{N}_{\mathrm{g}}(t):=\sum_{q, a, l} \mathrm{~N}_{(\mathrm{g}, \mathrm{a}, \mathrm{q}, \ell)}(t), \mathrm{g}=1, \ldots, \mathrm{C}, \mathrm{t}=0, \ldots, \mathrm{T}$.

STEP 3: Compute $d_{g}(t):=\max \left\{0, \bar{N}_{g}(t)-N_{g}(t)\right\}, g=1, \ldots, G$, $\mathrm{t}=0, \ldots, \mathrm{T}-1$.

$$
\mathrm{d}_{\mathrm{g}}(\mathrm{T}):=\overline{\mathrm{N}}_{\mathrm{g}}(\mathrm{T})-\mathrm{N}_{\mathrm{g}}(\mathrm{T}), \mathrm{g}=1, \ldots, \mathrm{G} \text {. }
$$

If some of these deviations are negative (only $\mathrm{d}_{\mathrm{g}}(\mathrm{T}), \mathrm{g}=1, \ldots, \mathrm{G}$ can be negative) there is no feasible solution. This is met by altering the conditions.

STEP 4: If $\mathrm{d}_{\mathrm{g}}(\mathrm{T})<0, \overline{\mathrm{N}}_{\mathrm{g}}(\mathrm{T}):=\mathrm{N}_{\mathrm{g}}(\mathrm{T}), \mathrm{d}_{\mathrm{g}}(\mathrm{T}):=0$. The changes in $\bar{N}_{g}(T)$ are 1 isted. If $d_{g}(t)=0$ for $g=1, \ldots, G$, $t=0, \ldots, T$ the problem is solved with the recruitment policy $R_{g}(t)$.

If not all deviations $d_{g}(t)$ are zero after STEP 4 we should try a more active recruitment policy. If not all $\mathrm{d}_{\mathrm{g}}(0)$ are equal to zero, the only way to satisfy the requirements is by recruiting $d_{g}(0) \mathrm{em}^{-}$ ployees in grade $g$ at time 0 .

STEP 5: $R_{g}(0):=\min \left\{d_{g}(0), R_{g}(0)\right\}, g=1, \ldots, G$,

$$
\begin{array}{ll}
\mathrm{R}_{\mathrm{g}}(\mathrm{t}):=0 \quad, \mathrm{~g}=1, \ldots, \mathrm{G}, \mathrm{t}=1,2, \ldots, \mathrm{T} \\
\overrightarrow{\mathrm{N}}_{\mathrm{g}}(0):=\min \left\{\overline{\mathrm{N}}_{\mathrm{g}}(0), \mathrm{N}_{\mathrm{g}}(0)+\widetilde{\mathrm{R}}_{\mathrm{g}}(0)\right\}
\end{array}
$$

changes in $\mathrm{N}_{\mathrm{g}}(0)$ are listed.

From now on we assume that the grade structure is linear. Moreover we assume that it is possible to derive, from the original model, the probabilities $q_{g g_{1}}(t)$ for finding an arbitrary employee $t$ years after his recruitment in grade $g$ in grade $g_{1}$ (see also [5]). After executing STEP 5 it should be computed how the newly recruited employe's $R_{g}(0)$ will affect the grade occupation in the rest of the planning period. This gives new deviations from target and bounds in the following way:

STEP 6: $N_{g}(t):=N_{g}(t)+\sum_{k=0}^{t} \sum_{g_{1}} R_{g_{1}}(k) q_{g_{1}} g(k), g_{1}=1, \ldots, g, t=0, \ldots, T$ 
$R_{g}(t):=R_{g}(t)+R_{g}(t), g=1, \ldots, r, t=0, \ldots, T$

$\tilde{\mathrm{R}}_{\mathrm{g}}(\mathrm{t}):=0, \mathrm{~g}=1, \ldots, \mathrm{G}, \mathrm{t}=0, \ldots, \mathrm{T}$.

Execute STEP 3.

Now STEP 4 has to be executed again in order to adapt unattainable targets. Next we might choose for $g=1$ the number of employees to be recruited at $t=1$ equal to $d_{1}(1)$. If $d_{1}(1)>\bar{R}_{1}(1)$ one might solve the bottleneck by an increase of $R_{1}(0)$, if possible. Otharwise the bound $\bar{N}_{1}$ ( 1 ) is adjusted. If this procedure leads to a violation of the targets at $t \times T$ it is again tried to solve the bottleneck by an increase of $R_{1}(0)$. This can be done by executir.t STEP 7 and STEP 8 . with $t=1$ and $g=1$.

$\operatorname{STEP} 7:$ If $\mathrm{d}_{g}(t) \leq \bar{R}_{g}(t), \widetilde{R}_{g}(t):=d_{g}(t)$ else $\widetilde{R}_{g}(t):=\bar{R}_{g}(t)$

$\tilde{R}_{g}(t-k):=\max \left\{0, \min \left\{\bar{R}_{g}(t-k)-k_{g}(t-k), \frac{d_{g}(t)-\sum_{l=0}^{k-1} \widetilde{R}_{g}(t-l) q_{g g}(l)}{q_{g g}(k)}\right\}\right\}$

for $k=1, \ldots, t$.

Execute STEP 6 .

$\overline{\mathrm{N}}_{g}(t):=\min \left\{\overline{\mathrm{N}}_{g}(t), N_{g}(t)\right\}$, clianges in $\bar{N}_{g}(t)$ are 1 isted.

Now it might occur that the target $\overline{\mathrm{N}}_{1}(\mathrm{~T})$ is violated i.e. $\mathrm{d}_{1}(\mathrm{~T})<0$. This means that there is a discrepancy between the lowerbound $N_{1}(1)$ and the target $\bar{N}_{1}(T)$. We try to solve this bottleneck by recruiting at an earlier time in grade 1.

STEP 8: If $d_{g}(T)<0$ define $k:=\max \left\{\ell<t \mid R_{g}(\ell) \neq \bar{R}_{g}(\ell)\right\}$, choose $\widetilde{R}_{\mathrm{g}}(\mathrm{k}) \geq 0$ such that:

1) $\tilde{R}_{g}(k) \leq \bar{R}_{g}(k)-R_{g}(k)$

2) $\widetilde{R}_{g}(k) \leq \frac{R_{g}(k+1)}{q_{g g}(1)}, \widetilde{R}_{g}(k+1):=-\widetilde{R}_{g}(k) \cdot q_{g g}(1)$

3) $\widetilde{R}_{g}(k) \cdot q_{g g}(T-k)-\widetilde{R}_{g}(k+1) q_{g g}(T-k-1)$ minimal but $\geq d_{g}(T)$.

Execute STEP 6, if $R_{g}(k+1)=0$ execute STEP 8 with $t=t-1$, else execute STEP 8 , Execute STEP 4.

We may proceed in this way by executing STEP 7 and STEP 8 for $g=1$ and $t=2,3, \ldots, T$ respectively. Then we go to $g=2$. Consecutive computation for $t=1,2, \ldots, T$ gives the results for grade 2 . Now it might be that $d_{2}\left(T^{\prime}\right)>0$ and $R_{2}(t)=\bar{R}_{2}(t)$ for all $t=0, \ldots, T$. 
This problem is triéd to be mut in a similar way as it was done for $\mathrm{N}_{1}(\mathrm{~T})$ (STEP 8) by recruiling in grade l at earlier times. How ever, the target $\bar{N}_{1}(1)$ is keep fixed. Then grade 3 may be treated in a similar way, etc.

In order to ensure that by executing STEp 8 already satisfied $10^{-}$ werbounds remain satisfied we have to impose an additional assumption on the transition probabilities $\mathrm{qgg}_{\mathrm{g}}(\mathrm{t})$. We assume

$$
q_{g g}(T-t) \leq q_{g g}(k) \cdot q_{g g}(T-t-k), \begin{aligned}
& 0 \leq t \leq T, k \leq T-t, \\
& g=1, \ldots, G .
\end{aligned}
$$

In the practical situations we met, this condition was fullfilled. Moreover, since in practical problems STEP 8 will be used, in general, only a very few times the condition may in fact be weakened. The method yjelds the requested recruitments and forecasted grade occupations, together with a list of corrections of the bounds and the targets in the original problem. This solution may be used for a discussion on the recruitment policy and the restraints and targets. The fact that this method does not try at any price to give a solution for the original problem is very essential and one of the main differences with the linear programming approach. It should again be emphasized, that in fact we treat only an example. This holds for the problem and the solution technique as well, viz. the depth of backtracking.

For example, which $\mathbb{N}_{\mathrm{g}}(t)$ are lowerbounds and which are targets may depend on the situation. As far as the solution technique concerns it depends on the practical requirements whether it might be simplified or not. For instance in a very simplified form step 7 and 8 might be omitted. On the other hand more sophisticated versions of the described dynamic planning technique may be constructed if this is required by the problem under study.

\section{The use of FORMASY}

We will not give an exhaustive overview of all the information that can be achieved by using the described tools. Merely, some examples will be given.

The basis for applying the techniques must be a Data Base containing the data of the current and former employees about their experiences in the manpower system over a certain number of years. It should be possible to obtain from this data base the following information:

a) The actual situation in the manpower system, i.e. $N(q, g, a, \ell)$
for all relevant states.

b) Information on transitions and occupancies of the states in the "recent" past, like $n_{-t}(s, \sigma)=$ the number of employees that were in state $s$ at time $t$ and jumped to state $\sigma$ in the next year.

With this information the matrix of transition probabilities can be estimated and the forecasts (with or without recruitment) can be computed. All these data cogether give fine possibilities to make 
lucid overviews (graphical and tabular) of the composition of the workforce in past, present and future. Very informative are plots of $\mathrm{N}_{\mathrm{g}}(t)$ as a function of $g$ for several values of $t$. Similarly

$$
\mathrm{N}_{(\mathrm{g}, \ell)}(\mathrm{t}):=\sum_{\mathrm{q}, \mathrm{a}} \mathrm{N}_{(\mathrm{g}, \mathrm{q}, \mathrm{a}, \ell)}(\mathrm{t})
$$

can be plotted as function of the grade age $\ell$ which illustrates the age distribution in each grade. For more examples we refer to [5].

As remarked in section 4, the most interesting use of the system is made when changes in $P$ are tried out. Such changes are made simply executable by some subprocedures which adjust the values of the transition probabilities for example in such a way that upperand lower holding time in a grade are increased or decreased with a given amount.

Some illustrative examples of such subprocedures will be indicated in the sequel of this section. In the examples we will use a model with only grade and grade age as essential characteristics. This is the type of model mentioned in section 2 for the engineers in the Dutch Ministry of Public Works. Employees in grade $g$ with grade age $\mathrm{n}$ are promoted to grade $\mathrm{g}+1$ with probability $\mathrm{p}((\mathrm{g}, \mathrm{n}),(\mathrm{g}+1,0))$. Since we will consider a fixed grade $g$, this probability will be denoted by $p_{n}$ in the sequel. For grade ages larger than $L$ we may suppose: $\mathrm{p}_{\mathrm{n}}=\mathrm{P}_{\mathrm{L}}$ if $\mathrm{n} \geq \mathrm{L}$. For simplicity we assume the probability to leave the system to be $p_{w}$, independent of the grade age.

Often manpower management formulates its promotion policy for grade $g$ in terms of the distribution of the holding time in grade 8 , without taking into account the possibility of leaving.

Let $P(n)$ be the fraction of employees who are promoted to grade $g+1$ after $n$ years (forgetting the possibility of leaving). Then the actual policy may be computed from

$$
P(n)=p_{n}\left(1-p_{w}\right)^{-(n+1)} \prod_{k=0}^{n-1}\left(1-p_{k}-p_{w}\right) .
$$

On the other hand, one can use this relation for the computation of new $P_{n}$ if new $P(n)$ are given and $P_{W}$ is supposed to remain the same:

$$
p_{n}=P(n)\left(1-p_{w}\right)^{n+1} \prod_{k=0}^{n-1}\left(1-p_{k}-p_{w}\right)^{-1} \quad \text { for } n=0,1, \ldots \text {. }
$$

By some simple subprocedures the holding time distribution $P(n)$, $\mathrm{n}=0,1, \ldots, \mathrm{n}$ and the average holding time

$$
\sum_{n=0}^{\infty} n P(n)
$$

may be computed. 
Furthermore a simple subprocedure allows one to insert a new holding time distribution or promotion policy and compute the relevant new transition probabilities. This kind of procedure enables one to compute very quickly the effect on the future manpower distribution of changes in promotion policy. In fact it enables one to find out what changes in promotion policy will be needed in order to obtain a desirable distribution over the grades.

This playing with promotion policies can be still more facilitated if one uses the following subprocedure. In this subprocedure the holding time distribution of the remaining staff is shifted one or more periods. So, if one calls this subprocedure for grade $g$ with shift +1 , then the $P(n)$ are computed and shifted in the following way

$$
P^{\prime}(0):=0, P^{\prime}(n):=P(n-1) \text { for } n=1,2, \ldots \text {. }
$$

Finally the new $p_{n}$ are computed from the new $P^{\prime}(n)$.

In this way the effects of simple changes in promotion policy can be tested easily and quickly.

The system is such that in a very short time several options can be worked out which appears to be very instructive for the manpower managers involved with manpower planning.

\section{References}

[1] Bartholomew, D.J., Stochastic models for social processes. 2nd. edition 1973, John Wiley and Sons, New York.

[2] Charnes, A., W.W. Cooper, R.J. Niehaus and D. Sholtz, A model for civilian manpower management and planning in the U.S. Navy, pp. 247-263 in [4].

[3] Forbes, A.F., The Kent model (1975), Report Institute of Manpower Studies, London.

[4] Smith, A.R. (ed.), Models for manpower systems, 1971, English University Press, London.

[5] Wessels, J. and J.A.E.E. van Nunen, FORMASY FOrecasting and Recruitment in MAnpower SYstems, Statistica Neerlandica 30 (1976), pp. 173-193. 